\title{
Datation des grottes ornées de l'Ardèche
}

Bidon, Saint-Martin d'Ardèche, Vallon-Pont-d'Arc

Julien Monney

\section{(2) OpenEdition}

\section{Journals}

Édition électronique

URL : http://journals.openedition.org/adlfi/3503

ISSN : 2114-0502

Éditeur

Ministère de la culture

Référence électronique

Julien Monney, « Datation des grottes ornées de l'Ardèche », ADLFI. Archéologie de la France-

Informations [En ligne], Rhône-Alpes, mis en ligne le 01 mars 2009, consulté le 01 mai 2019. URL:

http://journals.openedition.org/adlfi/3503

Ce document a été généré automatiquement le 1 mai 2019.

(c) Ministère de la Culture et de la Communication, CNRS 


\title{
Datation des grottes ornées de l'Ardèche
}

\author{
Bidon, Saint-Martin d'Ardèche, Vallon-Pont-d'Arc
}

Julien Monney

Identifiant de l'opération archéologique : 1022

Date de l'opération : 2009 (PC)

1 Le PCR Datation des Grottes Ornéesinitié en 2008 dans plusieurs grottes ornées paléolithiques des gorges de l'Ardèche s'est poursuivi en 2009. Il a essentiellement concerné trois sites dans lesquels toute une série d'opérations à vocation chronologique ont été menées : la grotte des Deux-Ouvertures, la grotte de la Tête-du-Lion et l'aven de la Genette.

2 L'objectif de ce projet est l'acquisition d'une meilleure connaissance chronologique des phases de fréquentation humaine et animale de ces cavités ainsi que de l'ornementation pariétale qu'elles contiennent au travers d'une pluralité d'approches chronologiques (Datation ${ }^{14} \mathrm{C}$ AMS de tracés pariétaux, de charbons en stratigraphie et d'ossements, mais aussi étude des modalités de fermeture des espaces ornés, etc.). L'idée générale est de développer une approche pluridisciplinaire permettant de croiser les données chronologiques issues de plusieurs domaines que ce soit au niveau chronométrique (datations ${ }^{14} \mathrm{C}, \mathrm{U} / \mathrm{Th}$, etc.) ou relatif (séquences de superposition, séquences stratigraphiques, etc.).

3 L'année 2008 avait principalement été dévolue aux prospections et aux inventaires. En 2009, les recherches se sont principalement centrées sur des opérations de prélèvements d'échantillons et des analyses.

4 À l'aven de laGenette et à la grotte des Deux-Ouvertures, plusieurs marques charbonneuses résultant sans doute d'impacts de torche ont été prélevées en vue de datations. De même, dans cette seconde cavité, des échantillons de charbon et de calcite ont été récoltés dans les strates de la formation carbonatée qui a fermé l'accès vers son 
secteur orné. Ces échantillons destinés respectivement aux datations par les méthodes du Carbone 14 et des déséquilibres dans la famille de l'Uranium (U/Th) se composent de charbons de bois $\left({ }^{14} \mathrm{C}\right)$ et de fragments calcite (U/Th). Comme charbon et calcite sont intimement liés, la comparaison des résultats des datations permettra de mieux comprendre le processus de formation de ce massif stalagmitique et de mieux cerner la date à laquelle il a clos le passage pour les Hommes et pour les Ours.

5 En parallèle, un scan 3D de l'ensemble de la cavité a été réalisé par l'équipe Edytem. Ce modèle numérique très précis est destiné à la compréhension des modalités de mise en place du massif stalagmitique ainsi qu'à la reconstitution de la morphologie passée des remplissages argileux dans les galeries fréquentées par les visiteurs paléolithiques. Il permettra aussi de mieux appréhender les écoulements d'eau dans la cavité et de servir de base lors des remontages photographiques nécessaires aux opérations de relevé des gravures pariétales (Fig. $\mathrm{n}^{\circ} 1$ : Relevé du Panneau de l'Angle comprenant entre autre le Mammouth DEE-12 et l'arrière-train indéterminé à l'ocre Ocr-06. On distingue au moins trois pattes et une trompe qui se prolongent vers le haut. Apparemment deux très grands mammouths complets s'étendent ainsi au-delà des limites du relevé réalisé cette année. Relevé : N. Lateur, S. Stocchetti, L. Baracchini, J. Monney.).

Des analyses de pigments en fluorescence $\mathrm{X}$ ont été menées à l'aide d'un appareil portatif. Cette méthode non-destructive permet de multiplier le nombre d'entités graphiques analysées sans avoir recours au moindre prélèvement. Parmi les tracés noirs de la grotte des Deux-Ouvertures, une marque s'est révélée être composée de manganèse et de silicium. Sa composition n'étant pas la même que celle des dépôts naturels environnants, la question de son caractère anthropique se pose. Sous toute réserve, il s'agirait alors du premier tracé au noir de manganèse formellement identifié dans la région. Par ailleurs, la démarche a permis la mise en évidence de quantités non négligeables de zinc au sein d'encroûtements noirs de parois. Cet élément inhabituel en contexte karstique pose la question de la génèse de ces dépôts.

$7 \mathrm{Au}$ cours du relevés des gravures de la grotte des Deux-Ouvertures, une figure fermant le dispositif pariétal a soulevé de nombreuses interrogations. En effet, malgré son caractère schématique, il pourrait s'agir d'un être composite mi-homme, mi-bovidé tel qu'on en connaît à Gabillou ou à Chauvet. Sa position, ainsi que son insertion au sein d'une composition complexe sont cohérentes avec cette hypothèse qui renforce l'idée d'un espace souterrain très structuré. De même, la tête d'un bison strié considéré jusqu'alors comme acéphale a été découverte lors des relevés. Elle est matérialisée par des reliefs naturels qui forment l'oeil (soulignés de quelques traits), le front, le fanon et les naseaux.

8 Quatre nouvelles dates ${ }^{14} \mathrm{C}$ AMS ont été obtenues. Les deux résultats provenant des prélèvements de 2007 sont parfaitement cohérents $\mathrm{du}$ point de vue chronostratigraphique et ils indiquent des âges compris entre 28000 BP et $29000 \mathrm{BP}$. Ces dates ont été obtenues sur des charbons bien en place, prélevés sur et sous un horizon induré (marquant un arrêt de sédimentation ou un sol de piétinement). Bien que d'autres phases de fréquentation paléolithiques du site soient probables, elles viennent questionner sur l'âge effectif des gravures pariétales du site. Elles fournissent un nouvel élément de discussion quant à la grande ancienneté de l'art pariétal dans la région GardArdèche-Hérault. Quant aux charbons prélevés en surface du sol, ils ont produit des résultats situés aux alentours de 5800 BP-6 500 BP. Leur localisation dans un secteur bien circonscrit de la cavité, au pied de la galerie montant vers la baume des Cloches laisse planer le doute quant au fait qu'ils témoignent de fréquentations effectives de la grotte au 
début du Néolithique. Il se pourrait en effet qu'ils soient arrivés là par soutirage des dépôts archéologiques de la baume des Cloches.

Enfin, à la grotte de la Tête-du-Lion, il a été procédé à un ravivage de coupe sur le bord du carré de fouille de 1963-1972. Cette opération a permis de collecter neuf échantillons de charbon (?) en stratigraphie. Ces éléments se présentaient sous forme de petites particules noires qui dans certains cas pourraient ne pas être du charbon. Elles se situaient cependant presque exclusivement au niveau altitudinal identifié en 1972 comme étant le niveau de fréquentation solutréen. Deux morceaux de planchers stalagmitiques coiffant la séquence sédimentaire ont également été prélevés. Enfin, le tamisage des déblais par tranches de $6 \mathrm{~cm}$ à $10 \mathrm{~cm}$ a permis de collecter quelques vestiges de microfaune. Ces vestiges concentrés sur le sommet de la stratigraphie permettront d'apporter quelques intéressantes précisions paléo-environnementales.

\section{ANNEXES}

Fig. $\mathrm{n}^{\circ} 1$ : Relevé du Panneau de l'Angle comprenant entre autre le Mammouth DEE-12 et l'arrièretrain indéterminé à l'ocre $0 \mathrm{cr}-06$. On distingue au moins trois pattes et une trompe qui se prolongent vers le haut. Apparemment deux très grands mammouths complets s'étendent ainsi audelà des limites du relevé réalisé cette année. Relevé : N. Lateur, S. Stocchetti, L. Baracchini, J. Monney.

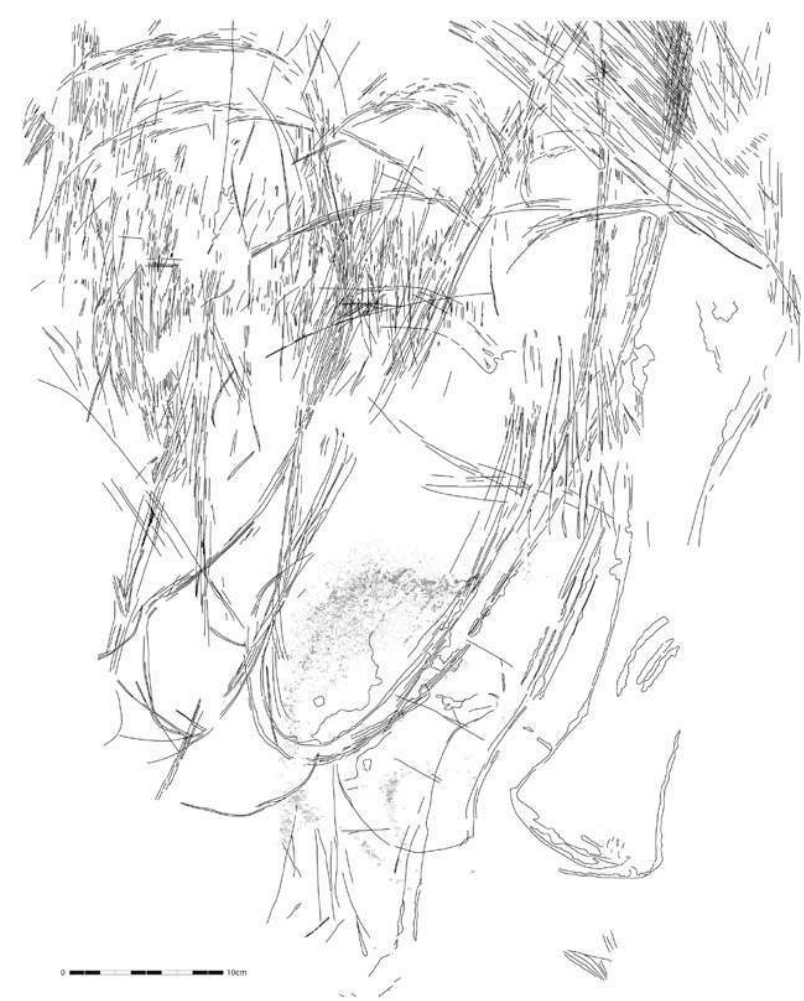


INDEX

Thèmes : analyse des matériaux, charbon, dessin, gravure pariétale, grotte ornée, mammouth, microfaune, pigment

operation Projet collectif de recherche (PCR)

Index géographique : Rhône-Alpes, Ardèche (07), Bidon

\section{AUTEUR}

JULIEN MONNEY

chercheur 